\title{
Los medios de comunicación de masas y las noticias como objeto de estudio de la sociología en la perspectiva del constructivismo operativo de Niklas Luhmann
} (2)

\author{
Mass Media and News as Sociological Objects of Study of Sociology \\ in the Perspective of Niklas Luhmann's Operational Constructivism
}

Gastón Becerra

Facultad de Ciencias Sociales, Universidad de Buenos Aires, Argentina

Vanessa Arreyes

Facultad de Ciencias Sociales, Universidad de Buenos Aires, Argentina

\section{Resumen}

\begin{abstract}
Este trabajo realiza una presentación crítica y sintética de la teoría de aquellos sistemas sociales denominados "medios de comunicación de masas" propuesta por Niklas Luhmann. Con este fin nos proponemos ubicar a los medios de comunicación de masas dentro de la teoría general de sistemas sociopoiéticos y describir los fundamentos epistémicos constructivistas - en la variante del "constructivismo operativo"- que subyacen a dicha teoría. Hacia el final nos enfocamos en cómo la teoría luhmanniana permite una descripción de los medios de comunicación de masas en la sociedad, la cual rescata una visión netamente sociológica.
\end{abstract}

Palabras Clave: Medios de Comunicación de Masas; Constructivismo Operativo;

Sistemas Sociopoiéticos; Noticias; Teoría de Sistemas Sociales

\begin{abstract}
This article presents a critical and synthetic view of the theory of the so- called "Mass Media" social systems, proposed by Niklas Luhmann. Therefore we aim to locate the mass media theory within the general theory of social sociopoietic systems and to describe its epistemic constructivist foundations -in the "operational constructivist" variant- . Towards the end of this article we focus on how Luhmann's theory allows a mass media description within society, which rescues a purely sociological vision.
\end{abstract}

Keywords: Mass Media; Operational Constructivism; Sociopoietic Systems; News; Social Systems Theory

\section{Introducción}

De acuerdo al sociólogo alemán Niklas Luhmann (2007), todo lo que sabemos acerca de la realidad, lo conocemos por los medios de comunicación de masas. Podemos mencionar varias razones que justifican el estudio sociológico de los medios de masas: su capacidad para circular discursos e imágenes sociales diversas entre un gran público y para producir sentido a partir de una lógica que les es propia y que se relaciona tanto con sus particularidades (i) histórico-burocráticas- técnicas como (ii) comunicativas (Saintout 2012; Aguado 2010). Si nos centramos en las primeras particularidades (i) veremos instituciones con un uso particular de la tecnología (siendo esta un factor de mayor o menor peso explicativo) situadas y relacionadas con otros agentes sociales en el campo de lucha de los símbolos sociales. Si nos centramos en las segundas (ii), veremos estudios en 
torno a cómo los medios de masas producen sus comunicaciones. Ambos planos no se encuentran nunca desligados, aunque la explicación sociológica haya subdeterminado el segundo aspecto en relación al primero (tanto en la perspectiva de la Escuela de Toronto como en las tesis frankfurtianas, v. Aguado 2010). En este trabajo sostenemos que la obra de Luhmann permite una caracterización donde se invierte dicha relación y se busca hacer foco en la dimensión social- comunicativa.

Dicho objetivo supone ver el funcionamiento de los medios de comunicación de masas en la sociedad. Es decir, indagar aquellos mecanismos sociales que los medios de comunicación de masas utilizan en su operar específico, mientras que a la vez, los relacionen con la sociedad que los engloba (por medio de una teoría de la sociedad). Por esto rechazamos inicialmente aquellos enfoques que describen y explican el accionar de los medios de comunicación de masas tanto fuera de los mismos medios como fuera de la sociedad. Nos estamos refiriendo a descripciones que recaen en un reduccionismo en torno a la persecución de objetivos económicos y políticos, o la manipulación de la información. No negamos que estos sean aspectos a considerar (y como veremos, ambos tienen cabida en la descripción luhmanniana) pero preferimos una explicación más compleja que permita preguntarnos en qué medida la sociedad y los medios masivos se determinan mutuamente y qué hay de socialmente relevante en las operaciones que reproducen al sistema denominado medios de comunicación de masas.

Comenzaremos con una caracterización general del dominio de fenómenos al que refiere la noción de medios de comunicación de masas; luego buscamos situar dicha caracterización en el plano de la teoría de sistemas sociopoiéticos de Niklas Luhmann, es decir, incorporando la noción de "sistema" para dicho dominio. Nuestro segundo objetivo para este trabajo será describir los fundamentos constructivistas que subyacen a la teoría, dando cuenta de la especificidad de la variante luhmanniana. A lo largo de dicho estudio analizaremos la dinámica propia que adquieren las noticias como campos programáticos que se diferencian al interior del sistema de los medios de comunicación de masas.

La idea central que tomamos del recorte de la obra de Luhmann en el que se centra este trabajo es que existen mecanismos generales a todos los sistemas sociales, y que dichos mecanismos se reespecifican al interior de éstos sistemas ganando su identidad en base a ciertas operaciones propias. Hacer foco en tales mecanismos nos permite anclar una explicación sociológica de los fenómenos relativos a los medios de comunicación de masas.

El texto capital de Luhmann en la materia se titula "La realidad de los medios de masas" (2000). Originalmente escrito en alemán en 1995, traducido y publicado en castellano en el 2000, dos años después de la muerte del autor. Es una obra breve pero madura y compleja que presupone la lectura previa de su arquitectura teórica (Almansa Martinez 2011), mientras que introduce nuevos conceptos (como el de "constructivismo operativo"), remitiendo a varias de sus exploraciones epistemológicas (tal vez el aspecto de su obra menos sistematizado). Además, a fin de obtener una presentación integral, revisamos también la obra póstuma e integradora de Niklas Luhmann "La sociedad de la sociedad" (2007), publicada originalmente en 1997 en alemán y traducida al castellano en 2007. Dicho texto tiene un antecedente en la obra "Teoría de la sociedad" (1991) que Luhmann escribe en el año 1991 y que aparece publicado al castellano en 1998, de la cual nos centraremos en el capítulo dedicado a los "medios de comunicación".

Antes de comenzar el estudio que nos hemos propuesto conviene dedicar unas líneas a la metodología de la observación de segundo orden. Partimos de que el sistema de medios de comunicación de masas no refleja la realidad sino que la construye por medio de la reproducción de sus operaciones selectivas, las cuales funcionan como observaciones. En estas observaciones y descripciones los medios de comunicación de masas 
sistemáticamente se autoexcluyen a fin de que la observación y descripción no aparezca como una autodescripción sino como una imagen fiel e inmediata de una realidad externa.

La noción de "observación" en Luhmann se define como la aplicación de un "esquema de diferencias" en/sobre el mundo - en el sentido más amplio posible: "como infinitud inobservable" (Luhmann 1998: 13)- con el objetivo de generar información para el sistema. La observación es una operación compleja que cuenta con dos componentes: la distinción y la indicación de la marca, que no pueden ser fusionadas o separadas (Luhmann 1996). La distinción que no pertenece a un lado o al otro resulta inobservada: es el "punto ciego" que en cada observación se presupone como la condición de su posibilidad. Lo que se dice desde algún punto gracias al uso de una distinción o un esquema (incluida esta oración), de modo tal que no puede haber observación neutral (si por esto entendemos: sin esquema, sin observador).

El basamento distintivo -es decir, basado en distinciones- de la observación le impone un tono continente y contingente. "Continente" porque tanto lo observado como lo noobservado se encuentra contenido en la forma de la observación. Raglianti (2006) aclara que la categoría "contingente" refiere a que: "lo observado depende de lo que el observador puede observar" (Raglianti 2006: 77) dando cuenta de que existen dos imposibilidades básicas en la observación: en primer lugar, no se puede observar todo, ya que dicho esfuerzo culminaría en duplicar la realidad sin por ello ganar información ni orden; en segundo lugar, "observar todo" implicaría ver el propio esquema que posibilita la observación junto con la observación. "Una observación requiere de una segunda observación para observar cómo observa" (Raglianti 2006: 77).

Este problema que Luhmann adopta como postulado - y que nos remite a la obra de Heinz von Foerster (2003)- concede las principales condiciones para un programa metodológico de investigación de corte constructivista: la observación de segundo orden o grado, en la cual se busca observar la observación de un observador, volviendo a incluirlo en una descripción tanto autológica como objetivante de la realidad (Arnold 1997; 1998). Es decir, al observar las distinciones utilizadas en las observaciones (lo que éstas permiten ver pero por sobre todo lo que éstas no permiten - su punto ciego) nos encontramos con un observador. Este es un segundo nivel de observación que - críticamente- no intenta ver lo mismo que el primero (lo que se ve) sino que pone el foco en la operación de observación ("cómo" se ve). Arnold (2003) presenta a la observación de segundo orden como una metodología, en tanto permite identificar "estructuras latentes" que el observador no puede observar durante la observación, aunque es su condición de posibilidad. Este es el correlato de los medios de comunicación de masas y su despliegue de una realidad de segundo orden.

\section{Caracterización de los medios de comunicación de masas}

Según Luhmann (2007: 2) los medios de comunicación masas tuvieron su apogeo en el siglo XX cuando una serie de inventos tecnológicos establecieron nuevas dimensiones para la distribución de la comunicación. Luhmann define al sistema de los medios de comunicación de masas como al conjunto de aquellas comunicaciones sociales que se sirven de medios técnicos de reproducción masiva para propagarse.

El concepto se distingue de la noción más abarcadora de "medios de comunicación" en la que incluimos al lenguaje y a la escritura. A la vez, es más específica que "medios de difusión" o "medios de propagación", ya que éstos refieren a las capacidades técnicas originadas con la imprenta, si bien éstas aparecen supuestas como "condición de posibilidad" del sistema. Así tales condicionamientos técnicos no serán vistos como su rasgo explicativo fundamental, de modo que el análisis luhmanniano se aparta del vicio tecnologicista y busca un enfoque enfático en los procesos sistémicos de corte sociológico. 
Para la teorización de Luhmann, el aspecto central del sistema de medios de comunicación de masas corresponde al acto comunicativo elemental: "entre el emisor y el receptor no debe haber interacción entre presentes" (2007: 3). Se trata de una comunicación que se encuentra "desacoplada" y requiere de una doble selección que no se puede coordinar en el mismo acto comunicativo: por un lado, el emisor (las organizaciones que producen la comunicación - a las que nos referiremos como "mass media") debe suponer por parte del receptor (el público masivo) el interés y la capacidad para aceptar su oferta comunicativa; mientras que por otro lado, el receptor debe suponer la disposición del emisor a generar dicha oferta. Esta conceptualización particular de la comunicación separa a los presupuestos de la obra de Luhmann de otros autores, como por ejemplo McLuhan, que ven en los medios de masas el despliegue de un sistema de "transmisión" (Taekke \& Paulsen 2010).

Poner el foco en este acto comunicativo desacoplado, donde la unidad del acto se gana a través de la recepción, supone importantes consecuencias para el análisis de los media. Las organizaciones que emiten comunicación no pueden pretender el consenso; no pueden garantizar una recepción individual acrítica pero tampoco pueden atender al modo en que cada individuo se apropie de la información (¿cómo podrían los emisores "negociar" un entendimiento con cada uno de sus destinatarios?) así como tan sólo pueden suponer por qué una comunicación tuvo o no aceptación individual; tampoco pueden pretender que toda la información emitida se comparta universalmente, ni sea tomada como completa y exclusiva (existen otros modos de conocimiento con otros focos y contenidos). En el desarrollo evolutivo del sistema, los emisores han generado estrategias a fin de operar en dichas condiciones. Por ejemplo, la diferenciación de géneros comunicativos muy específicos por medio del desarrollo de "programas" que estandarizan la comunicación destinada a un público específico (pero masivo) con un comportamiento receptivo particular. En términos que explicaremos a continuación, su operar es posible en la medida en que supone una suerte de memoria social compartida que hace innecesario preguntarse por los conocimientos de cada individuo. Los medios de comunicación de masas - en términos de García Blanco- "han de recurrir a suposiciones, lo que significa que, a fin de cuentas, los media son verdaderos generadores de profecías que se cumplen a sí mismas" (García Blanco 2003: 162).

En lo que respecta a los formatos y al alcance de esta definición conviene mencionar momentáneamente que el sistema de los medios de comunicación de masas en la teoría de Luhmann incluye tanto a las noticias, los formatos y programas informativos, como a la publicidad, propaganda y al entretenimiento (espectáculos masivos, series de televisión, revistas, etc.), siempre y cuando cumplan con las condiciones de masividad y distancia que se consiguen por el medio de la reproducción tecnológica.

Esta definición excluye a internet, entendida tanto como otro sistema en el entorno de los medios de comunicación de masas, o como medio para dicho sistema (Bastos 2011; Forte et al. 2012; Fuchs 2005). Incorporar a internet en un caso o en el otro supone un esfuerzo de acomodación teórica que excede el alcance de este artículo y que supondría preguntas como ¿qué cambios trae internet a la noción de "masas" la posibilidad de identificar y segmentar el público a partir de sus capacidades técnicas? ¿qué cambios supone internet como alternativa para la esfera de lo público y para la confianza que se pueda tener en los trabajadores de los media como profesionales de la comunicación? (Fuchs 2006; Baecker 2001). Esto sólo para mencionar algunas de las dimensiones que podemos anticipar como problemáticas, dejando fuera la indeterminación que internet presenta a la sociedad (Luhmann 2006). Por lo pronto partimos de la idea de que los medios de comunicación masiva - en los formatos listados anteriormente- aún juegan en nuestra sociedad un papel fundamental en la generación de discursos sociales e identidades comunes, y que internet hace eco de tales discursos en la misma medida en que permite cuestionarlos. 
La información que se difunde por los medios no es privada sino que busca ser de conocimiento general. Lo que se que se comunica reflejado en los medios es una realidad externa, ya que el "mundo íntimo" carece de relevancia para conformar un público. La "opinión pública" debe ser entendida fuera del horizonte de la experiencia individual, ya que ésta se relaciona con la primera por medio de una apropiación anónima y, por sobre todo, suelta. Esto implica que la opinión pública emerge y evoluciona a la par de los medios de comunicación de masas gracias a la masividad que estos permiten.

Aún más importante es destacar que para el funcionamiento de los medios de comunicación de masas, así como para la opinión pública a la que sirven, no es necesario reflejar acabadamente la realidad. De hecho, la distinción entre lo que ofrecen los medios y la realidad "tal cual es" sólo puede ser tratada excepcionalmente en los medios o sólo puede estar contenida marginalmente en la opinión pública.

\section{Los medios de comunicación de masas como sistemas sociopoiéticos}

Adentrarse en la lectura de la inmensa arquitectura conceptual de Luhmann requiere, en primer lugar, aclarar el dominio de fenómenos a los que refiere la teoría. Los sistemas se componen analíticamente de elementos relacionados (y un elemento sólo lo puede ser tal con respecto a un sistema específico). Para el caso de los "sistemas sociales autopoiéticos", o simplemente "sistemas sociopoiéticos" (de acuerdo al neologismo acuñado por Arnold 1999), Luhmann parte de determinar como elemento fundamental a las comunicaciones, presentando una alternativa teórica para la sociología, campo en el cual predominaron en las décadas anteriores las teorías de la acción (Stichweh 2001). Esto significa que para el caso del sistema de medios de comunicación de masas, los elementos no serán entonces los diarios, revistas, o programas de televisión, ni tampoco las organizaciones burocrático-jerárquicas (ni los individuos que en ellas participan) producen dichas comunicaciones, así como tampoco el público que la recibe. Una sociología sistémico- cibernética que tiene como su objeto a las comunicaciones no niega la existencia de individuos; de hecho los presupone como condición de posibilidad. Simplemente no los toma como su única garantía o último elemento en el que recae la observación y de los que se puede hablar de sentido u observación. Cuando los sistemas sociales toman este lugar, la explicación sociológica recae en el conjunto de comunicaciones ininterrumpidas (operaciones empíricas que acontecen en el tiempo y el espacio) que se presentan como realidades emergentes (Dallera 2012: 29) y que tienen como soporte a dichos actores corpóreos y productos reificados.

Así, entender a los medios de comunicación de masas bajo una lógica de reproducción sistémica nos aleja de los planteos sobre la "manipulación de la verdad" y la subsunción de las funciones mediáticas a los intereses de grupos económicos y el poder político. Es cierto que tales intereses políticos-económicos existen y que tiñen el tono de las noticias y los temas (Bourdieu 2012) pero, de acuerdo a Luhmann, no alcanzan a explicar acabadamente el funcionamiento de los media. Para el sociólogo alemán la "selección de las noticias" es un concepto que se debe referir a los medios de comunicación de masas en tanto un sistema social y no a sus organizaciones (mesa de noticias, redacción, línea editorial, etc.) "cuya libertad de decisión en la selección de las noticias es mucho menor de lo que con frecuencia se imaginan los críticos" (Luhmann 2007: 43). Así el sistema no es una cosa o un objeto, sino una distinción entre sistema/ entorno que se logra por medio de operaciones y que van dando forma constante y recursivamente a sus propios elementos y estructuras. De este modo, Luhmann desontologiza al mundo social, acercándose a una "epistemología operacional" que sigue explícitamente las huellas de Heinz von Foerster, Humberto Maturana y Jean Piaget (Luhmann 1998: 14). Además, en la medida en que la teoría hace foco en la figura del observador, relativiza cualquier 
descripción posible (la ambición universalista es necesariamente contingente, es decir, una descripción entre otras).

Vale aclarar que la comunicación no debe ser vista sólo como un elemento óntico, ni que el sistema debe definirse en última instancia por sus elementos. Luhmann insiste en que el foco del análisis debe residir en el concepto de "operación". Dado que la comunicación es un acontecimiento, su duración temporal es ínfima, y si el sistema se definiera sólo por sus elementos, carecería entonces de perdurabilidad. La estabilidad del sistema se consigue por medio de enlaces entre comunicaciones pasadas y subsiguiente en tanto "operaciones": "el objetivo no es la estabilidad estática sino la dinámica" (Luhmann 1997: 124). La comunicación cumple estos requisitos para ser entendida como operación fundamental de los sistemas sociales: “(la operación) debe ser una, la misma, y que tenga capacidad de eslabonar operaciones anteriores con subsecuentes. Es decir, capacidad de proseguir su operación y desechar (...) operaciones que no le pertenecen" (Luhmann 1996: 87). Este enlazamiento es selectivo ya que no se relacionan todas las comunicaciones entre sí (ni mucho menos se relacionan otros fenómenos o entidades no comunicativas como los sistemas psíquicos o las organizaciones), sino que el sistema recurre a un recorte en la cual se reduce la complejidad inaprehensible del mundo de lo posible hacia una complejidad estructurada por el sistema. En este enlazamiento selectivo se va delineando un sistema recursivo y complejo que se separa de un entorno.

Es necesario avanzar sobre la relación entre las nociones de "observación" y "operación". $\mathrm{Si}$ la operación básica del sistema de medios de comunicación de masas es la comunicación, ésta sólo puede referir a las observaciones que el sistema haga de la realidad. Esto toma un sentido aún importante para el sistema de los medios de masas, en tanto que la realidad de los medios de masas refiere tanto a lo observable desde los esquemas de los media, como a la realidad que estos ponen a disposición del público que confía en los media para comunicarles una observación de la sociedad. En estos términos, Luhmann sugiere ver el quehacer de los media como una secuencia de operaciones de observación en las que el sistema distingue entre una observación de sí mismos - la información transmitida- y de su entorno - temas- (Bechmann \& Ster 2011).

El observador también puede ser un analista (en este caso se habla desde el sistema ciencia, en su forma específica de la sociología) que recurre a un ejercicio de segundo grado de observación en los términos que hemos indicado: observar cómo el sistema observa. En términos de Granja Castro (2001), el "pensar sistémico" se caracteriza por observar operaciones autopoiéticas, es decir, trascender el plano del establecimiento de relaciones entre elementos y preguntarse por el nivel genético de las operaciones: ¿cómo ocurren los enlaces selectivos? ¿cómo es la dinámica que relaciona recursivamente a los elementos del sistema y la estructura que emerge de sus relaciones?

En lo que sigue contestaremos estas preguntas en relación a algunos conceptos fundamentales de la teoría de los sistemas sociopoiéticos, ilustrados con el caso particular del sistema de medios de comunicación de masas. Estos son: función, código, clausura operativa, autopoiesis y medios de comunicación simbólicamente generalizados.

\section{a) Función}

Cada sistema reproduce - con sus comunicaciones- una observación particular de la sociedad en su totalidad. A esta observación la llamamos "función". Dado que en una sociedad funcionalmente diferenciada coexisten diferentes sistemas que comunican en términos distintos, ninguna función puede ser fundamento último y completo de la sociedad. De acuerdo con lo que postula Luhmann (2006) las sociedades modernas son policéntricas y heterárquicas. $Y$ también por esto son sociedades complejas que han generado un sinfín de problemas contingentes. Por ejemplo, en sociedades donde el 
conocimiento no emana del principio de autoridad que ordena las relaciones sociales (poder), o que no descansa en la forma de lo sagrado (religión), se requiere de un sistema capaz de generar una comunicación sobre la verdad (ciencia). La descripción puede parecer paradójica (y sin duda lo es) ya que sigue la lógica de la evolución: variación, selección, reestabilización. Las soluciones aparecen junto a los problemas de forma casual. Que el sistema sea capaz de autoobservarse en estos términos y entienda la "función" como un "fin" (y para ello se oriente con medios, decisiones y acciones) es un problema de la reflexión del sistema mismo, de sus organizaciones y del uso interno del tiempo (Luhmann 1983; 1990).

La función del sistema de comunicación de masas es la autoobservación de la sociedad (Luhmann 2007: 139). Dichas observaciones no son operaciones aisladas, ya que - en tanto sistema- los medios de comunicación de masas remiten constantemente a operaciones previas, construyendo una "memoria social" que se reactualiza con estas nuevas observaciones. Dicha memoria supone no sólo el mecanismo de dar presencia (en términos temporales) a ciertas informaciones sino también el mecanismo del olvido, la omisión y el silencio. Aclaramos otra vez que dicho decir/omitir no puede ser solamente entendido en clave de interés sino que se debe reconocer como una limitación estructural: los medios de masas no pueden decir todo de todo ni tampoco lo pueden decir todo el tiempo.

Si bien esta autoobservación de la sociedad - y la resultante información que se genera en ella- constituye un conocimiento social entre otros, los logros histórico- evolutivos de los mass media les confieren una capacidad diferencial en relación a esta memoria. Pensemos, por ejemplo, en la capacidad de producir comunicación sin suponer (la mayoría de las veces) un tratamiento crítico-veritativo de lo que se comunica, aspecto que lo diferencia del conocimiento científico, el cual supone además cualificaciones altamente selectivas para la participación restringiendo la audiencia. Esta capacidad se debe entender como un logro histórico- evolutivo de los medios de masas que se han impuesto por sobre otros sitios de observación predominantes en otras formaciones sociales como sacerdotes, nobles y sabios (Luhmann 2007: 123). Estos últimos aparecen como alternativas al sistema, es decir, otros sistemas capaces de llevar a cabo operaciones que son funcionalmente equivalentes. Esto implica entender "función": en el sentido lógicomatemático del término "(...) como esquema lógico- regulador que permita comparar entre sí, como equivalentes funcionales, sucesos que desde otra perspectiva serían absolutamente incomparables" (Rodríguez 1995: XII).

Nos referimos a la "autoobservación de la sociedad" en tanto que: a) el objeto sobre el que el sistema de comunicación de masas comunica es la sociedad, y b) dicha observación se hace desde el interior de la sociedad misma y en nombre de ella.

Observar a/ Comunicar sobre la sociedad implica un recorte selectivo. No todo lo que ocurre en la sociedad se lo conoce, y no todo lo que se conoce se comunica. Constantemente el sistema de medios de comunicación de masas actualiza y refiere a una imagen de la sociedad que ha sido propuesta en comunicaciones anteriores desde el mismo sistema, o tematizado por el sistema a partir de comunicaciones de otros sistemas en el entorno (como cuando los media refieren a acontecimientos científicos o sobre medidas legales, convirtiéndolos en "información" por medio de notas de divulgación). La sociedad se presenta como un producto dinámico que se forja en secuencias de operaciones recursivas, de modo tal que es siempre una imagen relacional cuya estructuración depende del observador.

Aún más importante para el análisis sociológico resulta que los medios de comunicación de masas hablen en nombre de la sociedad. Este también es un resultado del desacople entre emisor y receptor que se puede rastrear a la historia de la emergencia de la escritura 
a partir de la cual se posibilita la comunicación entre vivos y muertos, o entre seres terrenales y dioses (Luhmann \& De Giorgi 1993: 115). Comunicar desde la sociedad (¿quién?) supone la reintroducción de esa imagen construida de la sociedad (¿qué?) en las comunicaciones ulteriores. No obstante, dicha comunicación lleva la condición de esconder su marca de producción. Todo se vuelve comunicable, excepto el hecho de que la voz con la que se comunica no es la propia. Explicitar que la realidad que el sistema comunica es la realidad del sistema y no la realidad facilitaría el rechazo (irreductible tanto por las condiciones mismas de la comunicación y profundizadas por el desacople). Sólo excepcional y circunstancialmente los media pueden cuestionar la veracidad de sus observaciones, y dicho cuestionamiento se debe tratar como una comunicación más en relación a dicha memoria. Es decir, el sistema funciona mientras que en las mismas comunicaciones en torno a lo público se lo considere confiable (Görke \& Scholl 2006), y no por la posibilidad de comparar la realidad propuesta con una realidad externa.

\section{b) Código y programas: las noticias}

Adoptar la noción de que los sistemas construyen una realidad dista mucho de sostener que se pueda decir cualquier cosa ("anything goes") o que la misma sea relativa (¿relativa con respecto a qué?). A lo sumo se puede decir que es una construcción arbitraria, pero se entiende que todas las construcciones autológicas lo son. Para los sistemas sociales esto implica que existe un esquema básico de distinción y selección sobre el que se montan sus comunicaciones. Dicho esquematismo es una estructura, es decir, una diferencia generada en las operaciones del sistema que se ha estabilizado en recursiones y que permite el procesamiento rápido de información en los términos que le son relevantes al sistema. Llamamos "código" a dicho esquematismo que adopta la "forma" de un conjunto cerrado de dos valores que excluyen terceros y más valores. Cualquier fenómeno puede ser atribuido a uno de los dos lados del código pero nunca a ambos al mismo momento.

En su evolución histórica, el sistema de comunicación de medios de masas ha estabilizado el código informable / no-informable. Ahora bien, si recordamos que los medios de masas incluyen además de los informativos a otros campos programáticos como la publicidad o el entretenimiento, en los cuales el valor informativo aparece menos nítido a partir de una relación diferencial con la categoría de realidad, tal vez convenga utilizar los términos más generales de presentable / no- presentable. A la vez esta estrategia nos acerca más a los "metacodigos" sistémicos de visible / invisible y comunicable / nocomunicable. Por otro lado, evita posibles confusiones de distinción del sistema de los medios de comunicación de masas con otros, en tanto todos operan produciendo información como selección de comunicaciones en el entorno (Aguado 2010: 203).

El código facilita el cambio de una referencia, ya que predefine para cualquier valor positivo uno negativo y viceversa (duplica así la realidad y la vuelve contingente). Lo que hoy se comunica como novedad pierde relevancia informativa en tiempos posteriores. Los valores del código no son simétricos: mientras el valor positivo tiende a enlazar las operaciones básicas del sistema (Luhmann se refiere a "códigos de preferencia"), el valor negativo suele llevar al sistema a la reflexión. Además resulta evidente que si no hubiera una realidad no- informada por el sistema, este debería duplicar totalmente la realidad perdiendo la capacidad de generar un recorte selectivo común lo que podría llevar a la muerte del sistema.

No obstante, recordemos que este es un escenario cuyas condiciones son posibles por el funcionamiento mismo del sistema que no requiere de una constatación de la recepción común, sino tan sólo de que su suposición/propuesta de que una realidad común existente sea aceptada al punto tal de que todas las comunicaciones deban empezar por referir constantemente a hechos que se suponen no conocidos, como si siempre nos comunicásemos con un extranjero con el cual no nos podemos referir a ninguna 
comunicación pasada. Para la evaluación de estos punteos conviene no confundir al sistema de comunicación de medios de masas con sus organizaciones, ni con la forma (plural o monopólica) que puede adquirir el mercado de los media.

Dado que los códigos no tienen criterios, sino que son sólo valores esquematizados que vuelven contingente a cualquier fenómeno observado, le corresponde a los "programas" proveer las condiciones con las que designa con un valor o su opuesto a un elemento del sistema. En otras palabras, los programas son conjunto de reglas de operaciones que permite la aplicación "correcta" de uno de los valores del código. Estas reglas aparecen como "enormes aparatos semánticos" complejos y variables (Luhmann 2006: 282), contrapuestos a la simplicidad, sencillez e invariabilidad del código.

De los distintos tipos de programas o reglas de selección de lo se puede informar (o no) es que podemos delimitar 3 grandes "campos programáticos": noticias, entretenimiento y publicidad. En lo que sigue haremos foco en el primero. Sin embargo, antes de continuar debemos detenernos en la advertencia - que Luhmann no evade (2007: 38)- de que dicha separación de programas persigue un objetivo de delimitación conceptual y que "en la realidad" los programas se encuentran estructuralmente acoplados ${ }^{1}$.

Tomando a las noticias, como formato que se reproduce en las operaciones de los medios de comunicación de masas, Luhmann realiza una observación de segundo orden y termina describiendo 9 "selectores" que hacen referencia a las condiciones de observación de dichas operaciones (Luhmann 2007: 44- 56):

1. el factor sorpresa (información nueva en referencia a acontecimientos únicos);

2. el predominio de los conflictos (ya que un enfrentamiento produce una situación de intriga y novedad por las posiciones de vencedor/ vencido)

3. el empleo de cantidades (ya que se pretenden informativas en sí mismas);

4. la cercanía (un caso local despierta mucho más la atención ya que condensa mucha más información y relevancia);

5. la personificación (como estrategia de simplificación que permite la adjudicación de culpas y causas pero también incita a la identificación);

6. la particularización (las referencias a otros casos "particulares");

7. la proliferación de opiniones y análisis tratados como sucesos en sí;

8. otro selector que cruza los anteriores es la inteligibilidad, en el sentido de que los medios deben reflejar la realidad de modo tal que su intelección sea asequible para el mayor número de público posible o al menos para que sea efectiva en relación con su público deseado (en este punto la agenda noticiosa se cruza fuertemente con las agendas institucionales comerciales de las corporaciones de noticias).

9. finalmente podemos mencionar un selector fundamental que cruza todos los anteriores: la contravención de normas sociales y la irritación de la moral. Este último selector explica por qué los casos que logran mayor exposición pública son generalmente casos extremos, y además da cuenta de cómo el accionar de los media funciona como una propuesta informativa que toma en consideración su entender de la moral social presente.

La posibilidad de explorar selectores es evidencia de que el constructivismo de los medios de comunicación de masas es criterioso". En términos de Sayago (2010: 292): “Las características de la configuración textual de las noticias está predeterminada por la necesidad de autolegitimación del Sistema de Medios de Comunicación Masiva: lo que se informa debe ser novedoso en algún sentido, debe ser relevante y debe ser presentado

\footnotetext{
${ }^{1}$ Para una crítica a la distinción luhmanniana a partir de sostener una "hibridación de operaciones y cánones estéticoexpresivos", cfr. Aguado 2010.

${ }^{2}$ En esta línea, Görke \& Scholl (2006) mencionan que la teoría de Luhmann ha sido utilizada en la investigación empírica sobre periodismo.
} 
narrativamente". Las noticias de mayor impacto son aquellas que obligan a tomar postura, que interpelan e interrogan al lector y le provocan asombro, sorpresa, indignación, compasión e ira (en los casos de noticias policiales esto se suele dar por medio de la "empatía con la víctima"). Así las noticias ponen el foco sobre la imagen que la sociedad tiene de sí misma y sobre los valores que se ven afectados, obligando a que los actores visibles se posicionen con respecto a ellos por medio de una valoración de la situación. A la realidad que observan los medios de comunicación de masas, se le opone constantemente "lo que debería ser", es decir, las valoraciones sociales ideales que forman parte de su observar (Luhmann 2007: 116). Dichas valoraciones (el ideal) - que en las operaciones se actualizan y reproducen- tienden a reforzar la primera selección (la realidad) convirtiéndola en un fundamento en sí mismo.

En la presentación que llevan a cabo los medios de masas, la contravención de normas toma el carácter de escándalo. El escándalo produce resonancia, aviva la escena y no permite que dichas contravenciones se presten a la justificación o a la disculpa (...) Los medios de masas hacen surgir como nadie, mediante informaciones sobre la contravención de las normas, la afectación colectiva y la indignación. (Luhmann 2007: 46)

Con esta persistencia de la moral en la realidad noticiada se acentúa en la unilateralidad de lo incluido frente a lo excluido. Las noticias no comunican sobre situaciones de repetición de lo habitual, de conformismo o de concordancia. Con la preeminencia de la discontinuidad y el conflicto la sociedad se estimula a sí misma para la producción de problemas que requieren soluciones (lo que es también un modo de producir recursivamente los elementos que ella misma requiere para su funcionamiento). "La sociedad, así, reproduce los temas que los medios de masas seleccionarán para transformarlos en información" (Luhmann 2007: 114). La descripción de Luhmann deja en la recursión de las comunicaciones y en la estructuración de "temas", a la generación de la agenda pública, superando la visión antagonista que postula en dicha noción una relación (generalmente en términos de "manipulación") asimétrica de los medios hacia la sociedad.

Las preguntas neurálgicas a las que apuntan las nociones de código y programa para el sistema de los medios de comunicación de masas en su formato noticioso son: ¿Qué descripciones de la realidad y de la sociedad aparecen en las noticias? ¿Qué ha quedado silenciado en ellas? ¿Qué clase de sociedad es la que permanentemente se informa a sí misma de ésta manera?

\section{c) Clausura operativa y autopoiesis}

La selección de la noticia es un proceso interno al sistema, en el que la información seleccionada - convertida en un caso o en una nota- se descontextualiza y pasa a ser un elemento. La noticia no puede serlo sin novedad; la novedad no se puede registrar sino en la memoria del sistema y en su propio registro del tiempo. El carácter autológico se vuelve claro en tanto el término información "no tiene un status objetivo" (Bechmann \& Stehr 2011: 146). Es decir, el sistema de los medios de comunicación de masas está constantemente seleccionando comunicaciones en tanto elementos de sí mismo para reproducirse (autopoiesis), en una escala temporal que le es propia, y por medio de operaciones que sólo se pueden controlar desde el sistema (clausura operativa). Para el campo programático de las noticias, esto implica la selección de casos, notas y novedades cada quince días, en forma semanal, diaria, o - con los portales de noticias de internet- , al instante.

Proveniente de la biología experimental de los biólogos chilenos Maturana y Varela, la incorporación de la autopoiesis ha sido polémica. Según Rodríguez y Torres (2003: 106), lo que habilita a Luhmann a hacer un uso "efectivo" del término es el hecho de haber 
sabido dar con una buena conceptualización de los elementos que forman y son formados en los sistemas de tipo sociales. Así la incorporación de la teoría de la autopoiesis a la sociología es posible en tanto se establece por medio de una abstracción sobre mecanismos o funciones entre ambos dominios y no sobre una analogía ontológica. Así Arnold (2003) acuña el término "sociopoiésis" para referirse a dicho proceso en el dominio particular de lo social. Con lo dicho se avanza también sobre la relación entre sistemas psíquicos y sociales (o los biológicos y los psíquicos...) hacia el acoplamiento de estructuras distintas: si bien se reconoce que ambos sistemas no pueden existir sin el otro, definirlos por medio de su clausura operativa les otorga una autonomía que excluye cualquier holismo o reduccionismo.

\section{d) Sobre los medios de comunicación simbólicamente generalizados}

Los medios de comunicación simbólicamente generalizados son estructuras que favorecen la probabilidad de aceptación de selecciones de sentido muy específicas, es decir, buscan asegurar que el receptor seleccione la oferta comunicativa del emisor para cierto tipo de comunicación. Tal incremento de probabilidad es posible gracias a cómo los medios combinan selección social con motivación individual. Existe una pluralidad de medios de comunicación simbólicamente generalizados y cada uno se orienta a una comunicación específica: el poder a la comunicación política, el dinero/propiedad a la económica, la verdad a la científica, etc.

El estudio de los medios de comunicación simbólicamente generalizado ha dado origen a un programa progresivo de investigación que cruza a varios autores y temáticas de las ciencias sociales (Mascareño 2009; Chernilo 2002). Parsons es el principal antecedente de Luhmann en relación a medios como el dinero, la influencia, el poder y los compromisos de valor. La innovación de Luhmann en este concepto surge de contextualizarlo en procesos comunicativos ( $y$ no de intercambio como en Parsons) junto a los problemas de la doble contingencia, permitiendo entender a éstos medios como estructuras que favorecen la motivación de selecciones, es decir, de la coordinación social en contextos de complejidad.

La comunicación desacoplada que los media llevan a cabo los exime de la necesidad de una aceptación stricto sensu para la reproducción de sus operaciones. Sin embargo, esto no excluye que podamos postular mecanismos que tiendan a reforzar la aceptación de la comunicación de los media: en este sentido proponemos al tándem "actualidad- novedad" como una reespecificación de la noción más general de "información" (Taekke \& Paulsen 2010). Aquí nos encontraríamos en una situación similar a la de los valores o de la verdad: frente a una información que se atribuye a una realidad externa pero que aparece como una vivencia del emisor, se pretende que el receptor también lo vivencie como propia. En el caso particular de la actualidad-novedad, la motivación para la aceptación de la comunicación viene dada por la posibilidad de participar de la memoria social compartida de un momento específico, en otras palabras, por la posibilidad de compartir un sentido común en relación a los temas sociales. Se puede aceptar una información que se comunica como novedad si se sabe que su elección obedece a los mecanismos de los media para observar la sociedad a partir de sus observaciones anteriores; al mismo tiempo, los media al acrecentar la probabilidad de la aceptación por medio de la pretensión de novedad obtienen su motivación para dicha comunicación. A la vez, el contenido moral de las selecciones noticiosas puede funcionar como un "código secundario" que se re- especifica al interior del sistema de los medios de comunicación de masas: lo que se comunica no se acepta sólo por ser novedoso, sino también, porque se propone como importante para el público. Si pensamos en la capacidad diferencial que tienen los medios de comunicación de masas en relación con otros sistemas, estas últimas notas nos permiten vislumbrar algunas respuestas a la pregunta final de la obra de Luhmann: “¿cómo es posible aceptar las informaciones sobre el mundo y sobre la sociedad 
como si se trataran de informaciones sobre la realidad, cuando se sabe cómo se produce esta información" (2007: 173).

\section{Conclusión y discusión}

Para finalizar conviene explicitar algunas líneas de consideración epistemológica sobre el conocimiento que circula en el sistema de los medios de comunicación de masas. En vistas de lo expuesto, queda claro que los mass media acceden a la realidad para recortarla y duplicarla. Nos adentramos entonces en el terreno del constructivismo por medio de operaciones de observación-selección. Luhmann refiere - en términos kantianos- que los medios de comunicación de masas "crean una ilusión trascendental" de la realidad, es decir, sus operaciones de comunicación funcionan como observaciones de una realidad externa para los medios y para quienes toman a la realidad como tal porque la han tomado de los medios (2007: 6). En otras palabras, se trata de una vivencia de realidad que se sustenta en las operaciones de un sistema social de comunicación y que se erige como realidad externa. En términos de Luhmann:

A diferencia de las teorías del conocimiento referidas al sujeto y que, a propósito, presuponen un mundo externo inaccesible (pero que han fracasado ante el problema de una mayoría de sujetos), el constructivismo operativo se fundamenta en la recursividad de las propias operaciones y en la memoria del sistema. Esta memoria se hace acompañar permanentemente de pruebas de consistencia de la operación sin que necesariamente se tenga que remitir a un sujeto. (Luhmann 2007: 131)

Esta postura ha recibido varias críticas $^{3}$ que adoptan la forma de la pregunta: ¿cómo podemos hablar de conocimiento (o de observación) para referirnos a otra cosa que no sean individuos? Debemos entonces recordar que por "cognición" entendemos la capacidad del sistema de estructurar un conocimiento coherente a partir de sus observaciones y en relación su propia memoria, reflexión y experiencia. La cibernética de autores como Heinz von Foerster apunta en este sentido. La innovación luhmanniana reside en situar a dicho constructivismo epistémico en sistemas de comunicación "empíricamente observables, operativamente cerrados y autorreferenciales" (Luhmann 1998: 72) a fin de dar cuenta de la producción social del sentido, es decir, llevar el plano de las operaciones al terreno del constructivismo social generando una alternativa al programa hermenéutico y su centro en las categorías de acción social e intersubjetividad.

En este sentido la clausura cognitiva aparece como condición tanto para individuos como para sistemas sociales. La observación (de segundo orden o grado) de la distinción que el sistema/ entorno da nuevas bases a la dicotomía sujeto/objeto, dando cuenta de los mecanismos de construcción de una realidad en la que el sistema se posiciona. En otras palabras, se trata de ver la observación como operación que utiliza distinciones que el sistema no puede indicar durante la operación misma y que funcionan como estructuras latentes pero que se vuelven observables con el auxilio de nuevas distinciones, es decir, nuevas operaciones para las que se reproducen las mismas condiciones de clausura cognitiva (Luhmann 1998). Para el caso aquí trabajado, nos referimos a la posibilidad de ver al sistema de medios de comunicación masiva en la sociedad desde el sistema de la ciencia con el auxilio del programa teórico de la sociología de sistemas. $\mathbf{R M}$

\footnotetext{
${ }^{3}$ Entre las más interesantes, ya que proponen como programa alternativo a la epistemología de Jean Piaget y Rolando García, puede consultarse a Cortés y Gil Antón (1997).
} 
Bibliografía

Aguado, J. M. (2010). Notas para una perspectiva constructivista del sistema de los media. IC- Revista científica de información y comunicación, 7, 193- 219.

Almansa Martinez, A. (2011). Reseña de 'La realidad de los medios de masas' de Niklas Luhmann. Razón y palabra, 75.

Arnold, M. (1997). Introducción a las epistemologías sistémico/constructivistas. Cinta de Moebio, 2.

Arnold, M. (1998). Recursos para la investigación sistémico-constructivista. Cinta de Moebio. 3.

Arnold, M. (2003). Fundamentos del constructivismo sociopoiético. Cinta de Moebio, 18.

Baecker, D. (2001). Niklas Luhmann in der Gesellschaft der Computer. Merkur, 55(7), 597609.

Bastos, M. T. (2011). Niklas Luhmann. A Social Systems Perspective on the Internet. Altitude: an e-journal of emerging humanities work, 9.

Benchmann, G. \& Stehr, N. (2011). Niklas Luhmann's theory of mass media. Society, 48(2), 142- 147.

Bourdieu, P. (2012). Cómo se forma la opinión pública. Le Monde Diplomatique, 15.

Chernilo, D. (2002). La teoría de los medios simbólicamente generalizados como programa progresivo de investigación. Revista Mad, 7.

Cortés, F. \& Gil Antón, M. (1997). El constructivismo genético y las ciencias sociales: Líneas básicas para una reorganización epistemológica. En R. García (Comp.), La epistemología genética y la ciencia contemporánea. Homenaje a Jean Piaget en su centenario (pp. 69-90). Mexico D.F.: El Colegio de México.

Dallera, O. (2012). La sociedad como sistema de comunicación. La teoría sociológica de Niklas Luhmann en 30 lecciones. Buenos Aires: Biblos.

Forte, M. A., Pignuoli Ocampo, S., Calise, S., Palacios, M., Zitello, M. (2012). Las TIC como problema de la teoría sociológica. Una aproximación conceptual desde la teoría general de sistemas sociales autorreferenciales y autopoiéticos. Revista de la Carrera de Sociología: Entramados y perspectivas, 2, 205- 226.

Fuchs, C. (2005). The Internet as a Self-Organizing Socio-Technological System. Cybernetics \& Human Knowing, 12(3), 57-81.

Fuchs, C. (2006). The Self- Organization of Cyberprotest. En K. Morgan, Konrad, C. Brebbia \& J. Spector (Eds.), The Internet Society II. Advances in Education, Comerce \& Governance (pp. 275- 295). Southampton/Boston: WIT Press.

García Blanco, J. M. (2003). La construcción de la realidad y la realidad de su construcción. Los mass media en la sociología de Niklas Luhmann. Revista DOXA Comunicación, 1, 149- 170.

Granja Castro, J. (2001). El pensar sistémico. Lógicas de razonamiento y horizonte de intelegibilidad en Niklas Luhmann. Metapolítica, 5(20), 90- 115.

Görke, A. \& Scholl, A. (2006). Niklas Luhmann's Theory of Social Systems and Journalism Research. Journalism Studies, 7(4), 644- 655.

Luhmann, N. (1983). Fin y racionalidad en los sistemas: sobre la función de los fines en los sistemas sociales. Madrid: Editora Nacional.

Luhmann, N. (1986). Love as Passion. The Codification of Intimacy. Cambridge: Harvard University Press.

Luhmann, N. (1990). Sociedad y sistema: La ambición de la teoría. Barcelona: Paidós.

Luhmann, N. (1996). Introducción a la teoría de sistemas. Lecciones publicadas por Javier Torres Nafarrate. Mexico D.F.: Universidad Iberoamericana.

Luhmann, N. (1998). ¿Cómo se pueden observar estructuras latentes?. En p. Watzlawick y P. Krieg (Comps), El ojo del observador: contribuciones al constructivismo. (pp. 6072). Barcelona: Gedisa.

Luhmann, N. (2007). La realidad de los medios de masas. Mexico D.F.: Universidad Iberoamericana/ Anthropos. 
Luhmann, N. \& De Giorgi, R. (1993). Teoría de la sociedad. Mexico D.F.: Universidad Iberoamericana / Triana.

Mascareño, A. (2009). Medios simbólicamente generalizados y el problema de la emergencia. Cinta de Moebio, 37.

Raglianti, F. (2006). Comunicación de una observación de segundo orden. Cinta de Moebio, 27.

Rodríguez, D. (1995). Introducción / Nota a la versión en español. En N. Luhmann, Poder. Barcelona: Anthropos Editorial.

Rodriguez, D. \& Torres N., J. (2003). Autopoiesis: la unidad de la diferencia. Luhmann y Maturana. Sociologías, 5(9), 106- 140.

Saintout, F. (2012). Los medios hablan de los jóvenes... y ellos responden. Juventudes en América Latina. Abordajes multidisciplinares sobre identidades, culturas y políticas, del siglo XX al siglo XXI. CAYCIT CONICET. Consultado el 10 de marzo, 2012, desde: http:// www.caicyt.gov.ar/files/ cdjuventudes/ contenido.html

Sayago, S. (2010). Pobreza y violencia en la prensa escrita. La irritación moral de la sociedad. Revista Texturas, 9- 10.

Stichweh, R. (2001). Teoría de sistemas versus teoría de la acción. La comunicación como opción teórica. Metapolítica, 5(20), 52-67.

Taekke, J. \& Paulsen, M. (2010). Luhmann and the media. MedieKultur, 49, 1- 10.

von Foerster, H. (2003). Understanding Understanding: Essays on Cybernetics and Cognition. New York: Springer.

\section{Sobre los autores}

Gastón Becerra es docente de la carrera de sociología en la Facultad de Ciencias Sociales de la Universidad de Buenos Aires, Argentina. Licenciado en sociología por la Universidad de Buenos Aires y doctorando en epistemología e historia de las ciencias por la Universidad de Tres de Febrero. Entre sus áreas de especialización se encuentran: epistemología de las ciencias sociales, teoría sociológica y metodología de la investigación social. Entre sus últimas publicaciones se destacan: Apuntes en torno a la relación entre sociogénesis del conocimiento y sociología de la ciencia (Universidad Nacional de Córdoba, 2011) y Las propuestas de lan Hacking y Judith Butler sobre lo socialmente construido (Revista Nómadas, 2011).

gastonbecerra@sociales.uba.ar

Vanessa Arreyes es estudiante de licenciatura en sociología en la Facultad de Ciencias Sociales de la Universidad de Buenos Aires, Argentina.

vanessa.arreyes@gmail.com

Contacto

Facultad de Ciencias Sociales

Universidad de Buenos Aires

Santiago del Estero 1029, C1075AAU

Ciudad Autónoma de Buenos Aires

Argentina

Recibido: Septiembre 2012

Aceptado: Octubre 2012 